\section{Stab wound leading to sub lingual haematoma}

\author{
CRAIG MILLER - MATHEW KEENAN • HELEN DREWERY • \\ NAYEEM ALI
}

$\operatorname{CRAIG~MILLER}(\square) \bullet$

MATHEW KEENAN •

HELEN DREWERY •

NAYEEM ALI

The Royal London Hospital

21 Kingsley Avenue

Borehamwood

Herts

WD6 4LY

United Kingdom

Phone: 07917272134

E-mail: cmiller09@qub.ac.uk

\begin{abstract}
We report a case of a sublingual haematoma and proptosis of the right eye as a result of penetrative injury to the suprazygomatic supratemporal fossa. The case was seen in the accident and emergency department at the Royal London Hospital $(R L H)$. The case was referred to the anaesthetic and oral and maxillofacial unit, following neurosurgery and ophthalmology assessments.

The case highlights the need for a multi disciplinary approach to dealing with penetrative wounds in the craniofacial region. It is essential that all healthcare professionals have excellent working knowledge of the anatomy of the orbit and its association with anatomical planes in the head and neck. (1) When diagnosing orbital compartment syndrome (also known as retrobulbar haemorrhage), radiographic findings should always be correlated to clinical signs and symptoms. Management of such a condition should be tailored to the individual. In this case medical management alone of $80 \mathrm{mg}$ of dexamethasone and 500mg of Mannitol was appropriate to enable a full recovery.
\end{abstract}

Key words: haematoma, airway obstruction, preoperative procedure, retrobulbar haemorrhage, floor of mouth

\section{Introduction}

A sublingual haematoma is an extremely rare occurrence as a result of a penetrative injury to the orbital apex or near the region of the suprasellar cistern. Such injuries can cause traumatic brain injury, intra cranial bleeds, orbital compartment syndrome and even lacerations of the optic nerve. (2) Without careful consideration of the clinical signs and symptoms, unnecessary surgery may have been performed on this patient.

\section{Case report}

A 32 year old male was taken to the Royal London Hospital (RLH) by ambulance at 4:53 am on 23/4/12, having been stabbed by a screw driver three times to the right pterion and once to the midline frontal region. He arrived on a spinal board in triple cervical spine protection. Medically he was previously known to be fit and well.

On presentation four wounds were evident (figure 1,2,3); he had a Glasgow Coma Scale score (GCS) of 15 , equal and reactive pupils and a proptosed right eye. A right sided neck swelling was also noted along with voice changes. Initial investigations consisted of clinical examination and a computed tomography (CT) scan of the head, neck and facial bones in axial, coronal and sagittal views.

The report confirmed multiple wounds, of which, two punctured the osseous calvarium. One of the tracks was into the right orbital apex with no optical nerve

involvement, causing a subperiosteal haematoma related to the roof of the right orbit. Further, a second track brea- ched the calvarium at the junction of the greater wing of the sphenoid bone with the squamous temporal bone (figure 4). There was evidence of intracranial penetration with an associated extradural haematoma. The cervical spine had been cleared and protection was removed. Following scans, he was transferred to an anaesthetic room because of a concern about his airway integrity. At this stage, nebulised adrenaline was used and the patient was able to maintain his own airway.

A Magnetic Resonance Imaging (MRI) showed that there was a haematoma involving the right prevertebral and parapharyngeal spaces. Further, Magnetic Resonance Angiography (MRA) was undertaken due to the location of the injury in relation to the cerebral arteries this showed that there was no significant vessel involvement. At 9:00am as there had been no deterioration in this gentleman's vision, he 


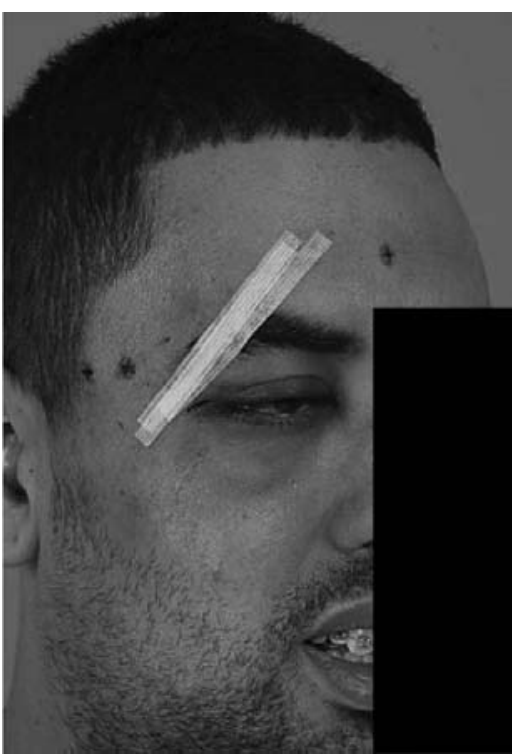

Figure 1. Right lateral view of stab wounds.

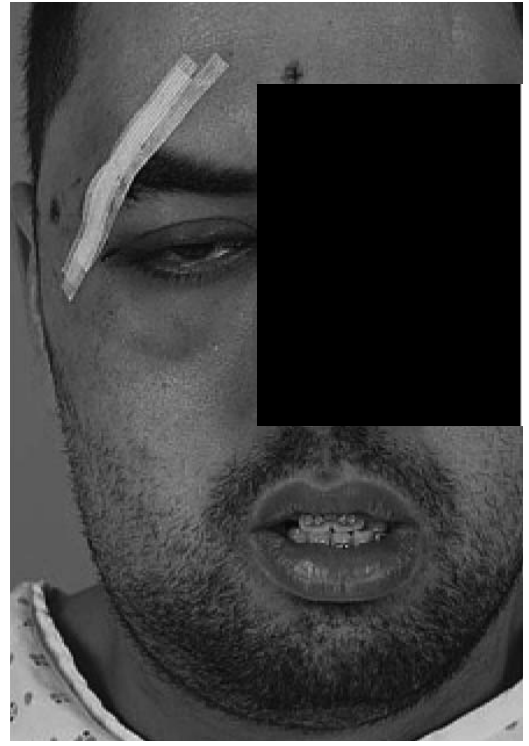

Figure 2. Anterior view of stab wounds.

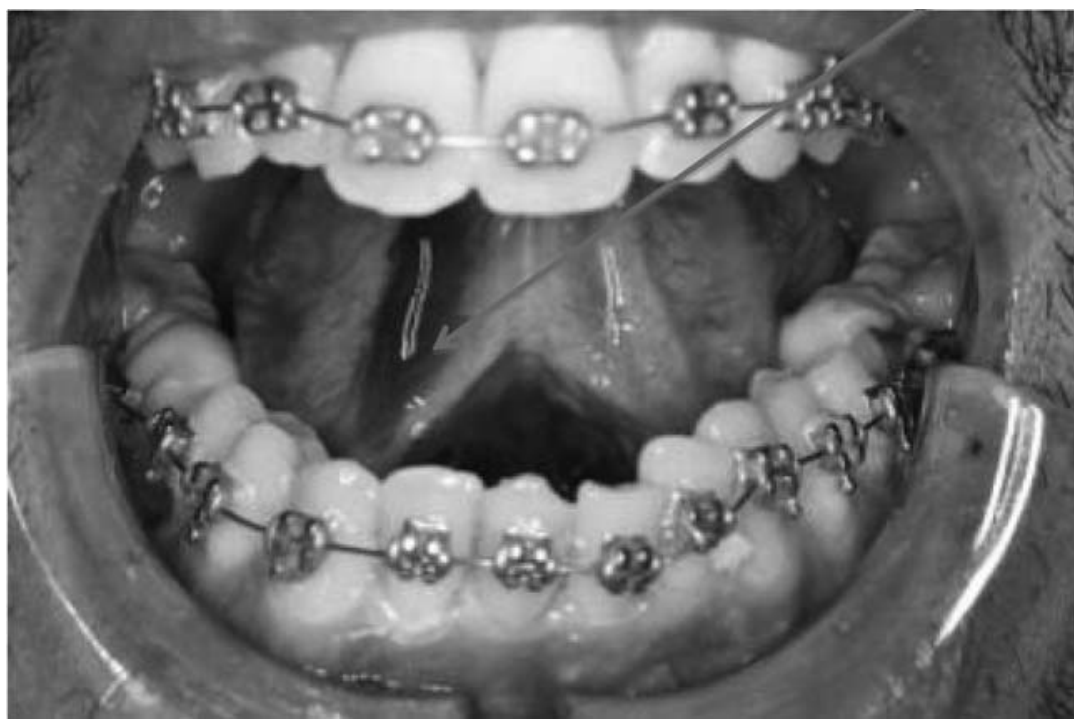

Figure 2. Sublingual haematoma.

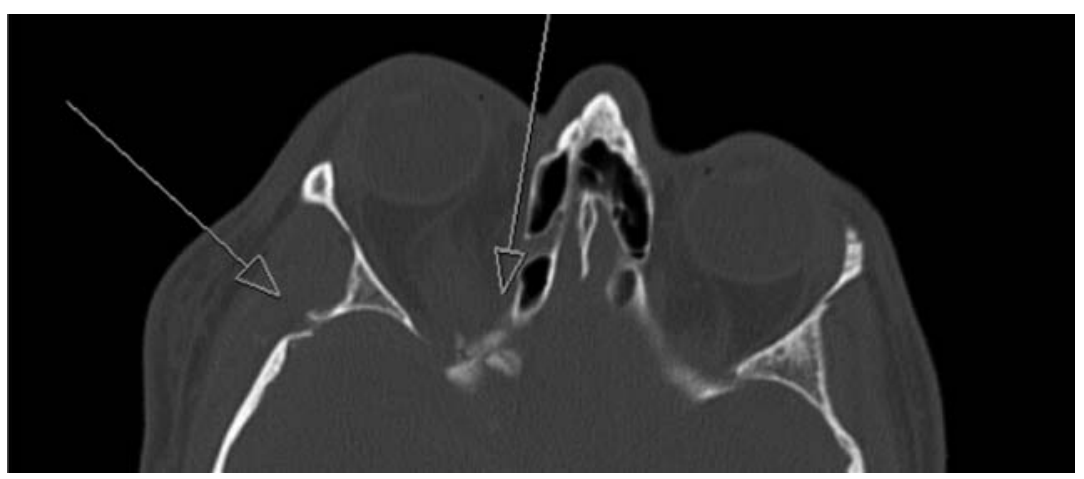

Figure 4. Computed tomography scan of stab wounds.

received $80 \mathrm{mg}$ of dexamethasone and $500 \mathrm{mg}$ of Mannitol to medically manage the proptosis of his right eye. He was subsequently taken from the anaesthetic room to the high dependency ward, where he underwent hourly eye and neurological observations. Once his neck swelling was no longer causing an airway concern he was transferred to the ward and placed on a regime of $8 \mathrm{mg}$ dexamethasone tablets and $1.2 \mathrm{~g}$ of coamoxiclav tablets for 24 hours. During this period further neurological and eye observations were carried out and both remained stable. Therefore, he was discharged at 10:00am on the 25/4/12.

\section{Discussion}

The presence of the sublingual haematoma (figure 3) is a known presentation of a fractured mandible. In this case it occurred as a result of blood that had tracked into the right parapharyngeal space, then subsequently into the sublingual space. Clinically, in this patient's case, the sublingual haematoma resulted in a raised tongue and gave the floor of mouth a red hue. On admission he was showing signs of stridor and voice changes. This improved with nebulised adrenaline. The neck and floor of the mouth swellings remained a concern and therefore close airway monitoring was needed in resus, the anaesthetic room and in the high dependency unit. Sublingual haematomas have the potential to cause severe airway disruption, mimicking a Ludwig's angina. (3) Checking the past medical history for blood dyscrasias and anti-coagulant medications is part of the initial management.

Orbital compartment syndrome is due to a bleed in the intraconal space, which causes an acute increase in orbital pressure. (4) This can lead to irreversible damage of the ocular and intra-orbital structures, possibly leading to blindness. It occurs in between $0.3 \%$ and $3.5 \%$ of facial traumas, and is a surgical emergency. A lateral canthotomy with decompression could prevent the loss of sight in an eye. (5) It can occur as a result of trauma to the orbits or as a postsurgical complication. In this 
case, the bleed behind the eye was less severe, and only resulted in a subperiosteal haematoma related to the roof of the orbit. Clinically, the eye was proptosed; however there was no restriction of eye movement, and the patient did not report any visual disturbances.
In light of the clinical picture, a conservative treatment plan was chosen, aimed at reducing the swelling behind the eye, and preventing any infection. Had airway intervention become necessary due to obstruction, there may have been the associated blood pressure changes with anaesthetics. This increase in blood pressure could potentially have lead to a worsening in intracranial bleeding and proptosis of the eye. Therefore high dose steroids, adrenaline nebulisers, an upright position and close monitoring were the safest option for this patient.

\section{REFERENCES}

1. Lima V, Burt B, Leibovitch I, Prabhakaran V, Goldberg RA, Selva D. Orbital compartment syndrome: the ophthalmic surgical emergency. Surv Opthalmol 2009;54:441-9.

2. Natrella M, Duc L, Lunardi G, Cristoferi M, Fanelli G, Meloni T. Treatment of a transorbital penetrating injury: a particular endovascular approach. Interv Neuroradiol 2012;18:191-4.

3. Cashman E, Shandilya M, Amin M, Hughes J, Walsh M. Warferin- enduced sublingual hematoma mimicking Ludwig angina: conservative management of a potential life-threatening condition. Ear nose throat j 2011;90:E1.

4. Allen $\mathrm{M}$, Perry $\mathrm{M}$, Burns $\mathrm{F}$. When is a retorbulbar haemorrhage not a retrobulbar heamorrhage? International $\mathrm{J}$ of Oral and Max fax surg 2010;39:1045-9

5. Brucoli M, Arcuri F, Giarda M, Benech R, Benech A. Surgical management of posttraumatic intraorbital hematoma. J Craniofac Surg 2012;23:58-61. 